\title{
Impediments to Patient-Physician Communication in a Hospital Setting
}

\section{Jacob M Litsey}

Communication is undoubtedly one of the most critical aspects of maintaining a healthy and strong relationship. Without constant, two-way communication, a marriage is bound to crumble under the weight of misunderstandings and unspoken words. The necessity of good communication, however, is obviously not limited to romantically involved relationships. A lack of effective communication can also lead to the ruination of friendships, poor workplace efficiency, and the erosion of the patientphysician relationship in a hospital setting (the topic of this paper). All too often within the realm of healthcare, patients feel as though their doctor is un-empathetic to their situation (although in actuality, this is rarely the case). They find themselves overwhelmed by the use of medical jargon from their attending physician, anxious in regard to the spectrum of potential diagnoses, and the time spent visiting with their physician rushed. All of these shortcomings, however, are not the result of a mass group of doctors who care little for their patients. And I certainly do not wish to paint doctors as individuals lacking emotions, who continuously fail to connect with their patients. Those persons who feel called to enter into the practice of medicine do so because they care so much about the human condition. Therefore, it is misplaced judgement to assume that potential inconsistencies in patient-physician communication fall entirely on the shoulders of the physician. Rather, I believe that it is the increasing corporatization of the medical field, in combination with a lack of intensive medical humanities training during undergraduate, that partly contributes to the creation of this communication barrier between patient and physician. By addressing these two contributing factors, I firmly believe that major strides can be made in improving patient-physician communication.

Like everything else, medicine has continuously evolved over time to meet the present demands of our society and the needs of human beings. The corporatization of the medical field was a necessary part of this evolution due to the rapid growth of the global population and the just pursuit of improving the quality of life for our fellow humans. Although this corporate takeover was inevitable and needed, its implementation was not met without undesirable outcomes. The involvement of drug companies, medical technology manufacturers, and corporate boards with margins to meet has placed additional strain on an already stressed out population of health care workers. These days, doctors are not only concerned with the health of their patients, but also with trying to see as many patients as possible in a given day in order to meet the demands of a business-modeled health care system. These pressures naturally affect the patient-doctor relationship and can impede good communication. Recalling my own past first-hand experience, I had the very fortunate opportunity to shadow a fantastic hospitalist over a period of several months. While shadowing this physician, we were often moving between multiple levels and wings of the hospital to keep up with each of her patients. The time spent with each patient was also limited due to the number of those assigned to her, as well as additional responsibilities of charting, daily meetings, and seeing newly admitted patients. Due to the short time frame allotted to each patient, doctors are often times forced to hit the "bullet points" of important information regarding the patient's diagnosis and prognosis. Therefore, it's easy to get lost in the use of medical jargon and worried over the potential worst-case scenarios of a disease or injury. 
This is one of the downsides of a corporatized health care system. Quality, one-on-one patientphysician interaction is limited by time constraints and the tendency to view patients as sources of income for the hospital (a view not held by the physicians necessarily, but the "industry" as a whole, to reiterate). What then, is a possible solution to this "fast-food" style of medical care? In truth, there is no one simple path to take that will put a reemphasis on the patient-physician interaction and thus improve communication between these two parties. Rather, there must be an effort on all fronts to reduce drug prices, restructure political involvement in health care, increase health education for all individuals (regardless of socio-economic status), and provide our physicians with more time to spend with their patients. Another way in which to improve patient-physician communication, and one which is unrelated to the corporatization of health care, is to increase medical humanities/ethics training and community involvement for pre-health and health care students.

Medical humanities and medical ethics courses are becoming more widely available across universities as the realization of the importance of these subjects continues to grow. I would like to argue, however, that medical humanities and clinical ethics should be part of the required pre-medical curriculum for those students wishing to work in health care (not just those seeking a medical degree). I also believe that community outreach programs targeted at helping the underprivileged and homeless should be more widely implemented by universities in order to increase students' exposure to the human condition. A background in these types of courses and easier access to becoming involved in community programs through universities would create a generation of medical students better prepared to communicate with their future patients.

It is important to note that the patient-physician communication barrier is a multifactorial issue, and therefore, it is safe to assume that there are number of additional elements to be considered outside of those addressed in this paper. One must also recognize that each patient-physician relationship is unique and dynamic in its own right, and thus generalizing every interaction to formulate solutions can be difficult. Realistically, an in-depth and extended research study would need to be conducted in order to develop effective solutions. The open discussion of this topic will at least begin the process of implementing the change necessary to further improve our health care system and thus improve the quality of life for our fellow humans. 